\title{
A Study on the Effect of Yoga on Sympathetic Nervous System
}

\author{
Athokpam Mirabai ${ }^{1}$, Tyngshainlang Sutnga ${ }^{2}$, Ningthoujam Sarada ${ }^{3}$ \\ ${ }^{I}$ (Visiting lecturer, College of Nursing, Medical Directorate,Manipur, India) \\ ${ }_{2}^{2}$ (Post graduate student, Department of Physiology, Regional Institute of Medical Sciences, Imphal, India) \\ ${ }^{3}$ (Professor, Department of Physiology, Regional Institute of Medical Sciences, Imphal, India)
}

\begin{abstract}
:
Background:Yoga is practiced in India and all over the world for over thousands of years.Increased awareness of health and natural remedies, yogic techniques are gaining importance and receiving worldwide acceptance.

Objective: To determine the effect of a set of yoga on sympathetic nervous system.

Methods: The study was conducted in fifty (50) normal females of Manipur undergoing three (3) months yoga training, in the age group 15-50 years.The study was a prospective study where sympathetic nervous system was assessed before the start of yoga training and after 3(three) months of yoga training under expert guidance. The parameters recorded were resting heart rate $(H R)$,resting blood pressure $(B P), B P$ response to standing and $B P$ response to handgrip.

Results: The resting cardiac parameters viz. $H R$ and BP were significantly lower after yoga training. After yoga training there was significant decrease in the BP during handgrip as well as during standing.

Conclusion: It can be concluded that the regular practice of a set of yoga training blunted the sympathetic drive and lateralised the autonomic function towards parasympathetic control.
\end{abstract}

Keywords:Sympathetic nervous system, Yoga training, hypothalamo-pituitary axis,cardiovascular morbidity and mortality.

\section{Introduction}

Yoga is an ancient science, which originated in India. ${ }^{1}$ Yoga includes diverse practices such as physical postures (asanās),regulated breathing (pranayama), meditation and lectures on philosophical aspects of Yoga. ${ }^{2}$ Everyone experiences stress because of our modern lifestyle which is highly competitive, challenging and with full of tensions. ${ }^{3}$ Chronic stress increases sympathetic discharge for a longer time and is characterised by a change in the set point of hypothalamo-pituitary axis activity, leading to immediate effect on heart rate, blood pressure, temperature, respiratory rate, catecholamines and corticosteroids. Thus sympathetic overactivity for a longer time is associated with cardiovascular morbidity and mortality. ${ }^{4}$ Such situation can be tackled by simple lifestyle modification including diet, exercise, Yoga and relaxation techniques. The present study was undertaken to ascertain that whether 3 (three) months yogic practices has any effect on the autonomic sympathetic nervous system, for reducing the cardiovascular morbidity and mortality.

\section{Materials And Methods}

The study was a prospective study conducted in the Department of Physiology, Regional Institute of Medical Sciences, RIMS, Imphal in collaboration with YTRC (Yoga Training and Research Centre Registration no. 38 of 1987), Imphal. Fifty (50) normal female volunteers of age group 15-55 years were included in the study. Only those who had never undergone yoga training were included in the study group. They were then subjected to undergo three (3) months of yoga training under expert guidance. The health of the subjects was assessed by taking history and performing general and systemic examination. A written informed consent was obtained from the participants after explaining the purpose of the study. The cardiovascular status was assessed by recording resting HR, resting BP, BP response to standing and BP response to handgripbefore the start of yoga training and after 3 months of yoga training.

On the day of the test,no cigarette, other nicotine containing food products, food or drugs per oral or any other route were permitted for three hours prior to the test. Before recording the above parameters, the procedures were explainedto the subject and subject was asked to relax physically and mentally for 30 minutes.The subjects were made to wear loosecloths and underclothings, metallic objects were not allowed to wear.The resting time after each test was 10 minutes.

Exclusion criteria:

1) Active sports training

2) Past yoga training

3) Pregnancy

DOI: 10.9790/0853-1605101316 www.iosrjournals.org 13|Page 
4) Smoking and alcohol consumption

All the subjects were given regular yoga training by an expert for a period of 3 months for 1 hour daily in between 7 am to 8 am for 6 days/week. The schedule is listed here:

a) On Monday, Tuesday, Thursday and Friday:

Breathing practices - 5 minutes.

Instant relaxation technique - 1 minutes.

Loosening exercise - 10 minutes.

Quick relaxation technique - 5 minutes.

Surya Namaskar - 3 minutes.

Asanas - 30 minutes.

Deep relaxation technique - 7 minutes.

b) On Wednesday:

Loosening exercise - 7 minutes

Surya Namaskar - 3 minutes

Pranayama - 50 minutes

c) On Saturday:

Loosening exercise - 30 minutes

Quick relaxation technique - 5 minutes

Surya Namaskar - 5 minute

Deep relaxation technique - 15 minutes

The following parameters were done in the specific sequence as given below:

1) Resting Heart Rate:

Apparatus: Electrograph (Cardiart 108/ MK ECG Machine).

Procedure: Lead II of ECG was selected for recording HR. Calibration was done and maintained throughout the procedures. Tracing speed was $25 \mathrm{~mm} / \mathrm{sec}$.HR was recorded in supine position by conventional method during normal quite breathing for a period of $1 \mathrm{~min}$. The average R-R interval were measured manually and $\mathrm{HR}$ was calculated (HR=1500/R-R interval).

2) Resting Blood Pressure (Systolic and Diastolic BP):

Apparatus: Mercury Sphygmomanometer (Diamond), Stethoscope (Microtone).

Procedure: BP was recorded with a mercury sphygmomanometer in supine position in right upper limb by auscultatory method using a stethoscope. Three (3) reading were taken at an interval of 15 minutes each and average of the three values was calculated.

3) BP response to standing:

Apparatus: Mercury sphygmomanometer (Diamond), stethoscope (Microtone)

Procedure: After 5 minutes of rest in supine position, resting BP was recorded. Then the subject was asked to stand up immediately and remain still without movement. BP was recorded after 0.5 minute, 1 minute and 3 minutes in the erect posture.

4) BP response to sustained handgrip:

Apparatus: Handgrip dynamometer (25kg model IMI-2095, India Medico Instruments, Delhi), mercurial sphygmomanometer, stethoscope (Microtone)

Procedure: A basal BP was recorded in sitting position first. Then the subject performed maximum grip of the handgrip dynamometer and the maximum capacity from the graduation marking was noted down. After 5 minutes rest, the subject was asked to hold the grip with $30 \%$ of the maximum capacity for 6 minutes. While performing this sustained handgrip, BP was recorded every 2 minutes. Near the end of the performance (at the end of 6 minutes), BP recorded just before the release of the grip was noted.

Data Analysis

Statistical analysis was done by using paired "t" test.

\section{Results}

The results obtained are expressed as mean \pm standard deviation. The age of the subjects ranges from 15-55 years (mean age 35 years). 
Table 1: Comparison of resting heart rate before and after yoga training

\begin{tabular}{|c|c|c|c|}
\hline Test & $\begin{array}{c}\text { Before yoga } \\
(\text { mean } \pm \text { SD) }\end{array}$ & $\begin{array}{c}\text { After yoga } \\
(\text { mean } \pm \text { SD })\end{array}$ & p-value \\
\hline Resting heartrate (beats/min) & $78.72 \pm 8.27$ & $70.24 \pm 5.24$ & $0.000^{* *}$ \\
\hline
\end{tabular}

$* *$ indicates highly significant $(\mathrm{p}<0.05)$ value

Table 1 shows thecomparison of resting heart rate before and after yoga training. The mean resting heart rate before yoga training is $78.72 \pm 8.27$ beats $/ \mathrm{min}$ and it significantly decreases $(\mathrm{p}=0.000)$ to $70.24 \pm 5.24$ beats $/ \mathrm{min}$ after yoga training.

Table 2: Resting systolic BP and systolic BP response to standing before and after yoga training

\begin{tabular}{|l|c|c|c|}
\hline \multicolumn{1}{|c|}{ Tests } & $\begin{array}{c}\text { Before yoga } \\
(\text { mean } \pm \text { SD) }\end{array}$ & $\begin{array}{c}\text { After yoga } \\
(\mathbf{m e a n} \pm \text { SD) }\end{array}$ & p-value \\
\hline RestingSBP (mmHg) & $125.56 \pm 7.43$ & $116.64 \pm 5.82$ & $0.000^{* *}$ \\
\hline 0.5 minSBP $(\mathbf{m m H g})$ & $125.92 \pm 10.18$ & $115.56 \pm 7.11$ & $0.000^{* *}$ \\
\hline $\mathbf{1}$ minSBP $(\mathbf{m m H g})$ & $124.76 \pm 8.32$ & $114.28 \pm 7.08$ & $0.000^{* *}$ \\
\hline 3 minSBP (mmHg) & $125.16 \pm 7.22$ & $115.52 \pm 6.12$ & $0.000^{* *}$ \\
\hline
\end{tabular}

**indicates highly significant $(\mathrm{p}<0.05)$ value

Table 2 shows the resting systolic BP and systolic BP response to standing before and after yoga training.The resting systolic BP significantly decreases $(\mathrm{p}=0.000)$ from $125.56 \pm 7.43 \mathrm{mmHg}$ to $116.64 \pm 5.82 \mathrm{mmHg}$. Results for systolic blood pressure response to standing at 0.5 minute, 1 minute and 3 minutes show significant decrease after yoga training.

Table 3: Resting diastolic BP and diastolic BP response to standing before and after yoga training

\begin{tabular}{|l|c|c|c|}
\hline \multicolumn{1}{|c|}{ Tests } & Before yoga $($ mean \pm SD) & $\begin{array}{c}\text { After yoga } \\
\text { (mean } \pm \text { SD) }\end{array}$ & p-value \\
\hline Resting DBP (mmHg) & $81.40 \pm 6.051$ & $74.24 \pm 5.431$ & $0.000^{* *}$ \\
\hline 0.5 min DBP (mmHg) & $85.72 \pm 6.857$ & $80.80 \pm 5.014$ & $0.000^{* *}$ \\
\hline 1 min DBP (mmHg) & $85.32 \pm 6.015$ & $81.24 \pm 5.868$ & $0.000^{* *}$ \\
\hline 3 $\mathbf{m i n}$ DBP (mmHg) & $83.04 \pm 5.514$ & $77.00 \pm 6.848$ & $0.000^{* *}$ \\
\hline
\end{tabular}

$* *$ indicates highly significant $(\mathrm{p}<0.05)$ value

Table 3 shows resting diastolic BP and diastolic BP response to standing before and after yoga training. The resting diastolic BP significantly decreases $(\mathrm{p}=0.000)$ from $81.40 \pm 6.051 \mathrm{mmHg}$ to $74.24 \pm 5.431 \mathrm{mmHg}$. Results for diastolic blood pressure response to standing at 0.5 minute, 1 minute and 3 minutes show significant decrease after yoga training.

Table 4: Blood pressure response to sustained handgrip before and after yoga training

\begin{tabular}{|c|c|c|c|}
\hline Tests & Before yoga $($ mean \pm SD) & $\begin{array}{c}\text { After yoga } \\
(\text { mean } \pm \text { SD) }\end{array}$ & p-value \\
\hline SBP $(\mathbf{m m H g})$ & $143 \pm 9.76$ & $146 \pm 8.04$ & 0.05 \\
\hline DBP $(\mathbf{m m H g})$ & $99.16 \pm 7.51$ & $93.12 \pm 7.49$ & $0.000^{* *}$ \\
\hline
\end{tabular}

**indicates highly significant $(\mathrm{p}<0.05)$ value

Table 4 shows blood pressure response to sustained handgrip before and after yoga training. It is found that SBP response to sustained handgrip increases from $143 \pm 9.76 \mathrm{mmHg}$ to $146 \pm 8.04 \mathrm{mmHg}$ and DBP response to sustained handgrip shows significant decrease from $99.16 \pm 7.51 \mathrm{mmHg}$ to $93.12 \pm 7.49 \mathrm{mmHg}(\mathrm{p}=0.000)$.

\section{Discussion}

In the present study, on analyzing the effect of a set of yoga in 50 healthy subjects of age 15 to 55 years, it was found that there is a highly significant reduction in the resting heart rate, systolic and diastolic blood pressure after 3months of yoga training. There is also highly significant decrease in BP response to standing after Yoga training which is similar to the finding of Desh et al. ${ }^{5}$ The results also shows significant decrease in DBP rise to handgrip test but there is non significant increase of SBP rise in response to handgrip test after Yoga training. Reduction in resting HR and resting BP indicates an altered autonomic balanced in the subjects practicing Yoga training with a tilt towards parasympathetic dominance. ${ }^{8}$ A significantly lower response of DBP due to handgrip indicates a lower sympathetic drives after Yoga training. Reduction of sympathetic over activity ensures better peripheral circulation and blood flow to tissues by decreasing arterial tone and peripheral resistances . 7,9,10 These modulation of autonomic nervous system activity might have been brought about through the conditioning effects of Yoga on autonomic function involving limbic systemand higher areas of central nervous system. ${ }^{11}$

DOI: 10.9790/0853-1605101316 www.iosrjournals.org 15|Page 


\section{Conclusion}

With increased awareness and interest in health, one should adopt the non-pharmacological methods like Yoga exercise, meditation and lifestyle modification to control the modifiable risk factors responsible for cardiovascular morbidity and mortality.It can be concluded that Yogic techniques may affect the autonomic activity significantly blunting the sympathetic discharge and might help in reducing psychosomatic disorders.

\section{References}

[1] Vivekananda Kendra, Yoga the exercise of holistic living, Chennai: Vivekananda Kendra Prakashan Trust, 2005.

[2] Nagendra HR, Yoga its basis and application, Bangalore: Swami Vivekananda Yoga Prakashan, 2005.

[3] Raichur RN, Kulkarni SB, Rahul RR, Aruna GB, Sridevi RR, Effect of meditation training on pulmonary function tests, Rec Res Sci Tech, 2(11), 2010, 11-16.

[4] Pal GK, VelkumaryS ,Madanmohan, Effect of short-term practice of breathing exerciseson autonomic functions in normal human volunteers, Indian J Med Res, 120, 2004, 115-121.

[5] Desh D, Sinha AN, Gusain VS. A study on effects of meditation on parasympathetic nervous system functional status in meditators, Intl J Res Pharma Biomed Sci,3(2) 2012, 772-779.

[6] Santha J, Sridharan K, Patel SKB, Kumaria ML, Selvamurthy W. Joseph NT et al,Study of some physiological and biochemical parameters in subjects undergoing yogic training, Indian J Med Res, 74, 1981, 120-124.

[7] Anand BK, Yoga and medical sciences, Indian J PhysiolPharmacol, 35(2), 1991, 84-87.

[8] Khurana RK, Setty A. The value of the isometric hanggrip test studies in various autonomic disorders,ClinAuton Res, 6, 1996, 2128.

[9] Vyas R, Dikshit N, Effect of meditation on respiratory system, cardiovascular system and lipid profile, Indian J PhysiolPharmacol, 46(4), 2002, 487-491.

[10] Bhargava R, Gogate MG, MascarenhasJ,Auonomic responses to breath holding and its variation following pranayama, Indian $\mathbf{J}$ PhysiolPharmacol, 32(4), 1988, 257-264.

[11] Selvamurthy W, Nayar HS, Joseph NT, Joseph S, Physiological effects of yogic practices,Nimhans Journal, 1(1), 1983, 71-80. 